\title{
INTELIGENCIA ARTIFICIAL: LA CIBERNÉTICA DEL SER VIVO Y DE LA MÁQUINA
}

\author{
Miguel Acosta \\ Universidad San Pablo-CEU Madrid
}

Resumen: La complejidad de los sistemas informáticos actuales y la sofisticación a la que se ha llegado con los ordenadores nos sorprende cada vez más. Hoy día se ofrece una alta automatización en el tratamiento de datos y en la elaboración de cálculos lógico-matemáticos de procesos complejos. Esto ha persuadido a muchas personas acerca de la posibilidad de que los ordenadores puedan realmente pensar o que un dispositivo digital sustituya al cerebro. Sin embargo, hay diferencias radicales que se observan entre el pensamiento humano y el procesamiento de datos del ordenador. Me gustaría analizar cuáles son esas diferencias.

Palabras clave: Inteligencia Humana, Inteligencia artificial, Cibernética, Tecnología, Teoría del Conocimiento, Ontología, Filosofía de la Naturaleza, Aristóteles, Jacinto Choza.

Artificial Intelligence. The cybernetics of living being and the machine

Abstract: The complexity of current computer systems and the sophistication that has come with computers surprises us more and more. Today, high automation is offered in data processing and in the elaboration of logicalmathematical calculations of complex processes. This has persuaded many people about the possibility that computers can really think or that a digital device replaces the brain. However, there are radical differences that are observed between human thinking and computer data processing. I would like to analyze what those differences are.

Keywords: Human Intelligence, Artificial Intelligence, Cybernetics, Technology, Theory of Knowledge, Ontology, Philosophy of Nature, Aristotle, Jacinto Choza.

Recibido: 19/10/2018 Aprobado: 20/02/2019 


\section{Introducción}

La inteligencia es una de las capacidades más especiales del ser humano y signo de diferenciación con otras especies: somos el zoón noetikós de Aristóteles.

La inteligencia artificial procura emular la inteligencia natural, y mucha gente está convencida de que, con el tiempo y los avances que se están llevando a cabo en este campo, las máquinas podrán igualar e incluso superar a la inteligencia humana.

Hay personas como Ray Kurzweil (Cfr. Kurzweil, 2005) que pronostican una transformación de la IA que superaría las capacidades humanas, una especie de elaboración de Terminators que no solo matan sino que son máquinas que crean otras máquinas "inteligentes". Otros, como Anthony Levandowski, ingeniero que impulsó el desarrollo de coches de conducción automática para Google y Uber, llegan incluso a crear una nueva religión para "desarrollar y promover la realización de una deidad basada en la inteligencia artificial y que, mediante la comprensión y la adoración a dicha Deidad, se contribuya al mejoramiento de la sociedad" (Brandon, 2018), porque piensa que dios emergerá concretamente en el 2042 y escribirá una nueva Biblia.

Además, grandes empresas como Amazon, Google, Apple o Facebook están invirtiendo miles de millones de dólares en $\mathrm{I}+\mathrm{D}+\mathrm{i}$ en tecnología de Inteligencia artificial; en EEUU e Inglaterra hay empresas que ofrecen financiaciones a largo plazo, como el proyecto denominado "Cien años de estudios sobre la Inteligencia Artificial” de la Universidad de Stanford que durará hasta el 2030 (Cfr. https://ai100.stanford.edu/); y es un hecho que en los últimos años ha habido una auténtica avalancha de artículos y eventos relacionados con el tema, y se han iniciado numerosos grupos de investigación.

Más allá de que todo esto forme parte de una estrategia para atraer sponsors, lo que sí sabemos es que el estado evolutivo de la Inteligencia Artificial 
hoy no es el que nos hace creer el gran despliegue publicitario al que asistimos. A veces, lamentablemente, hay mucha falta de sinceridad.

Las empresas Expensify, Scale o Edison Software entre otras, tenían a ingenieros leyendo cientos de miles de correos para responder a emails de forma inteligente, humanos tecleando en tiempo real los recibos que los usuarios mandaban con su teléfono a través de la "tecnología smartscan" para tener estas facturas transcritas. El asistente virtual de Messenger de Facebook son personas de carne y hueso. ${ }^{1}$

Me gustaría aclarar la confusión que generan las analogías y metáforas usadas respecto a la IA con el fin de desmitificar ciertas ideas que se propagan con la "marca" Inteligencia Artificial, en su sentido fuerte. Y en segundo lugar, analizar la cibernética de los seres vivos junto con la cibernética de la inteligencia artificial propuesta por Jacinto Choza, desde la Ontología clásica (Platón-Aristóteles) y desde la Teoría General de Sistemas de Ludwig von Bertalanffy.

No pretendo restar mérito a los avances en este campo, o minusvalorarlos. Al contrario, no solo admiro y aliento el desarrollo tecnológico de la IA, sino que me parece que desde la filosofía hay que acompañar el análisis de este fenómeno.

\section{Un término exitoso y la profecía de Turing.}

El término "Inteligencia Artificial" es impactante. Es probablemente uno de los casos más exitosos de branding de los últimos tiempos. En efecto, hay marcas que se posicionaron más allá de lo que ofrecían sus productos. Por ejemplo: Coca-Cola, que comenzó en 1886 y se expandió por todo el mundo. Su marca y diseño ya forman parte de la historia cultural del siglo XX y XXI. Otro ejemplo exitoso es el logotipo de la manzana mordida de

${ }^{1}$ Ver: https://magnet.xataka.com/preguntas-no-tan-frecuentes/ias-no-te-van-quitar-trabajogranjas-bots-humanos-descubiertas-escandalo-gmail (Última visita: 17 julio 2018). 
Apple, cuyos fans proponen curiosas interpretaciones acerca su significado, desde una referencia a Adán y Eva hasta un tributo a Alan Turing, que murió al morder una manzana envenenada de cianuro... ¿Pero quién acuñó el término "Inteligencia Artificial"?

Durante el verano de 1956 algunos científicos se reunieron en un Congreso en Darmouth (New Hampshire, USA) para debatir acerca de cómo hacer máquinas que se comportasen inteligentemente. En concreto, se partía de la conjetura de que cada aspecto del aprendizaje o cualquier otra característica de la inteligencia, en principio pueden ser descritos de forma tan precisa que una máquina podría ser programada para simularla. (Cfr. McCorduck, 2004: 111)

Algunos participantes como Allen Newel y Herbert Simon preferían el término "Procesamiento complejo de información" que es lo que literalmente hacen los ordenadores, pero John McCarthy, organizador del evento, insistió en que el nombre Inteligencia Artificial llamaría la atención y atraería muchos artículos. (Cfr. McCorduck, 2004: 115)

Me atrevo a hacer un paralelismo de lo que representó en el ámbito tecnológico el Congreso de Darmouth de 1956 con el del primer Congreso Solvay de 1911 en el ámbito de la física. Fue un punto de partida revolucionario que aceleró el desarrollo tecnológico del siglo XXI. Así, hoy tenemos Cloud Computing (la Nube), Big Data, Blockchains (sistemas hiperseguros) y Bitcoins, Realidad Virtual, Internet de las Cosas, Robots, Vehículos Autónomos y Fábricas Oscuras, Impresión 3D, Biología Sintética, Autoensamblaje Molecular, Computación Cuántica y Orgánica, entre otros. (Cfr. Barnatt, 2017). Sin mencionar la ingente producción literaria y filmográfica de ciencia ficción en torno a la IA.

La técnica y la tecnología tienen como objeto desarrollar productos con un propósito determinado: ayudar a potenciar las capacidades humanas. Se trata de algo construido por el ser humano, algo que no aparece como resultado de la evolución natural. La naturaleza nos ha sido dada, nosotros no hemos intervenido en ella, pero tras millones de años de evolución aparecimos como una especie dotada de capacidades singulares, entre las que 
destaca sobre todo la capacidad de advertir y tratar lo "inmaterial". Y eso hace que nuestro modo de vida sea especialmente distinto.

Aunque los ordenadores no forman parte de la evolución porque no son seres naturales, Alan Turing, considerado como el padre de la Inteligencia Artificial, en su artículo Computing Machinery and Intelligence (Cfr. Turing, 1950a), planteó una desafiante pregunta filosófica: ¿las máquinas pueden pensar? Allí también expuso su famoso "juego de imitación”. En este artículo Turing acertó cuando dijo: “[...] creo que a finales del siglo, el uso de las palabras y de la opinión educada en general, habrán cambiado tanto que uno podrá hablar de máquinas pensantes sin esperar ser contradicho." (Turing, 1950b: 8; Cfr. Turing, 1950a, 442) Esta profecía se ha cumplido. Hoy día, hay personas que creen de verdad que "las máquinas piensan" gracias a una inteligencia artificial.

Llama la atención cómo en muchos informes oficiales o publicaciones científicas sobre la IA, incluso en científicos, hay una gran falta de rigor al utilizar algunos conceptos o expresiones técnicas, sobre todo por no considerar el sentido que tiene una palabra según el área de conocimiento que se trate. Así, se usan expresiones tautológicas y generalistas que reducen o pervierten el sentido propio del término. Por dar un ejemplo, en el siguiente extracto del Informe Oficial del Panel sobre los 100 años de la Inteligencia Artificial de la Universidad de Stanford (Cfr. Stanford University: https://ai100.stanford.edu/, 2018), se puede advertir falta de rigor y ambigüedad en el uso del concepto inteligencia y cómo es atribuida a la IA: "La inteligencia artificial es aquella actividad dedicada a hacer que las máquinas sean inteligentes, y la inteligencia es esa cualidad que permite a una entidad funcionar adecuadamente y con previsión en su entorno." (Nilsson, 2010) Las definiciones de "inteligencia artificial" e "inteligencia" del Informe Oficial, tiene como fuente una monografía académica del ingeniero informático Nils J. Nilsson. Pero, el autor del citado informe oficial ¿no tendría que haber utilizado fuentes autorizadas para definir el concepto "inteligencia" que tiene un sentido propiamente filosófico y, a partir de ahí, ser más específico con el concepto de "inteligencia artificial" o incluso 
usarlo en sentido análogo? Un informe oficial no es un mero artículo de divulgación, donde se permiten ciertas licencias, sino que establece conclusiones que pretenden ser rigurosas y científicas. Este tipo de descuidos es frecuente y con el uso ciertos conceptos análogos se pueden convertir fácilmente en unívocos.

\section{Diferencias esenciales entre lo natural y lo artificial}

$\mathrm{Al}$ parecer no resulta tan obvia la diferencia entre inteligencia humana e inteligencia artificial, sobre todo si tenemos en cuenta que varios filósofos y científicos piensan que somos máquinas o casi como máquinas. Nos vienen a la memoria Descartes, de la Mettrie, Monod... autores que sostienen algún tipo de filosofía materialista. En palabras de Thomas Nagel:

El materialismo es el punto de vista que sostiene que solamente el mundo físico es irreductiblemente real y que la mente, si es que existe tal cosa, debe encontrar su cabida en él. Esta posición continuaría el progreso de la ciencia física, a través de la biología molecular, para clausurarla del todo incorporando la mente a la realidad física objetiva de la cual fue inicialmente excluida. Lo que esta postura cree es que la física carece de problemas filosóficos y el objetivo principal al que se opone es la imagen dualista de Descartes del fantasma en la máquina. (Nagel, 2014: 63)

A la hora de contrastar ambas inteligencias, el primer punto de distinción evidente está dado por el concepto "natural", ya que lo "artificial" es justamente lo que se opone a lo natural. Lo natural es lo que surge sin la intervención elaboradora, poiética, del ser humano. Es decir, se trata de todos los seres que han ido apareciendo, vivos o no vivos, desde el origen del universo, a través de un proceso evolutivo. En este proceso, el ser humano ha sido un elemento más, muy diferente a otros seres, pero a la postre, un 
ser más. Sin embargo, el fenómeno que marca una diferencia neta con lo artificial es el de la vida.

La vida no es una "construcción" humana, aunque contribuya a su reproducción.

Los biólogos dicen que, al parecer, la vida ha surgido de una bacteria —una célula procariota que carece de núcleo—. Se piensa que el hipotético primer organismo, LUCA (Last Universal Common Ancestor), dio lugar a tres dominios: bacteria, archaea y eukaria; y que solamente la Eukaria ha dado lugar a una complejidad creciente que se observa en el desarrollo de la Naturaleza desde hace como 4.000 millones de años. (Cfr. Butticaz, 2016: 23) El Homo Sapiens Sapiens es el ser más evolucionado que se conoce, debido a sus peculiares capacidades de conocer, obrar y poseer sentimientos.

Con respecto a la inteligencia, no cabe duda que el encéfalo humano posee la mayor complejidad de sistema nervioso entre los seres vivos. Aún así, no sabemos lo más básico de nuestra existencia: qué es la vida.

Según Nicolás Jouve, entre otros muchos científicos, "no existe un enunciado claro del concepto, de manera que más que definirlo lo que procede es precisar sus propiedades." (Jouve, 2008: 185) Desde la perspectiva de la ciencia, la mejor aproximación al fenómeno de la vida proviene de la Genética, que centra su estudio en torno a la capacidad de reproducción y evolución a lo largo de las generaciones. El más ínfimo tipo de vida es esencialmente diferente del ordenador más complejo que pueda existir. Baste pensar que la evolución es un proceso continuo y que ha comenzado a partir de una célula. ¿Cómo de poderoso sería el contenido de esa célula para iniciar un proceso tan complejo como el de la evolución?

En su obra ¿Qqué es la vida?, Schrödinger, habla de dos mecanismos para producir acontecimientos ordenados: 1) el que crea "una corriente de orden a partir del desorden" que es el normal de la Naturaleza física y es el que ha seguido al Big Bang; y 2) el que produce "orden a partir del orden", que escapa de la descomposición en el caos atómico y "absorbe orden" de un ambiente apropiado, propia de la biología que mantiene la vida. "No podemos esperar, — dice Schrödinger- que las 'leyes de la física' [...] basten 
para explicar el comportamiento de la materia viva, cuyos rasgos más fascinantes están visiblemente basados en el principio del 'orden a partir del orden”". (Schrödinger, 2001: 124) ${ }^{2}$

¿Sería absurdo preguntarse si el ser humano podrá "construir" vida? Si un ser humano construyera una vida fuera del proceso natural se trataría de una vida artificial, resultado de su poíesis. Aun así, ¿̇es posible crear ese tipo de vida "artificial"? Parece que sí, de eso va la llamada "biología sintética".

El 2 de julio de 2010, la revista Science publicó un artículo acerca de la manufacturación de la célula de una bacteria sintética auto replicante (etiquetada como JCVI-syn1.0) llevada a cabo por la J. Craig Venter Institute (JCVI). Fue construida con 1.078 componentes del ADN diseñados, ensamblados y trasplantados en una bacteria denominada Mycoplasma capricolum. La célula fue "activada" eléctricamente y obtuvieron una nueva forma de vida. Esto demostró que los genomas pueden ser diseñados en el ordenador, hechos químicamente en el laboratorio y trasplantados en una célula recipiente para producir una nueva célula auto replicante controlada sólo por un genoma sintético. Según Craig Venter, se trataba de la primera forma de vida auto replicante que tiene por "padre" a un ordenador (otra analogía extrínseca que pretende impactar).

En mayo de 2015, la compañía SGI-DNI, relacionada con el instituto de Craig Venter, lanzó la primera impresora de ADN, la BIOXp 3200. Se trata de una máquina que permite a cualquier compañía tecnológica o laboratorio académico crear genes, elementos genéticos y herramientas moleculares en sus laboratorios, comenzando con una secuencia de datos transmitida electrónicamente. El 28 de junio de 2016, el Instituto Craig Venter produjo la

2 "En Biología, nos enfrentamos con una situación completamente diferente. Un único grupo de átomos, del que existe una sola copia, produce acontecimientos ordenadamente, armonizados entre sí de modo maravilloso y con el ambiente siguiendo las leyes más sutiles. [...] Es un simple hecho de observación que el principio director de cada célula está contenido en una asociación atómica única existente sólo en una copia (o algunas veces en dos copias) y un hecho de observación el que todo ello produce sucesos que constituyen un modelo de orden—." (Schrödinger, 2001: 122-23) 
primera célula sintética hecha a partir de "partes redundantes" de una célula viva natural. (Cfr. Barnatt, 2017: 84-86) ${ }^{3}$ Podemos comenzar a imaginarnos el negocio que se está llevando a cabo con esta tecnología en estos momentos.

Estamos ante un caso de manipulación genética que tiene una relación directa con la vida e indirecta con la inteligencia artificial, y por supuesto acarrea consecuencias reales que merecen un detenido análisis ético. ${ }^{4}$

\section{La cibernética del ser vivo y de las máquinas}

Una vez efectuada la aproximación científica sobre la vida, abordaré el tema desde un punto de vista filosófico siguiendo especialmente a Jacinto Choza.

[V]ida significa capacidad de realizar operaciones por sí mismo y desde sî mismo, o sea, recoger y transmitir información autónomamente por parte del emisor-receptor. Esto es lo que en algunas formas del lenguaje filosófico se denomina inmanencia. [...] Inmanencia significa que hay un símismo en el ser vivo que permanece siempre y en el cual permanecen también los efectos de las operaciones realizadas, del recoger y transmitir información. (Choza, 1988: 27)

El "quedarse dentro" del ser vivo significa que hay algo que permanece junto con las operaciones realizadas, que recoge y transmite información. El término "información" se usa analógicamente en diferentes ámbitos: biología (ADN), ingeniería, informática, ciencias de la información, filosofía...

\footnotetext{
${ }^{3}$ También ofrecen Open Software como el GenoCAD que incluye grandes librerías de partes genéticas, junto con las reglas que describen el modo de combinación de la construcción genética funcional.

${ }^{4}$ Otro tema que ha surgido a raíz de los dispositivos tecnológicos relacionados con la salud es la implantación de dispositivos digitales en el cuerpo humano para suplir funciones de algunos órganos o miembros, o para incrementarlas. Es el caso de los ciborgs que no trataré en este estudio.
} 
En sentido propio, la información es el intercambio de un mensaje entre un receptor y un emisor.

Además de la característica distintiva del "quedarse dentro" o "inmanencia" del ser vivo, Choza también menciona el elemento esencial de la vida: la psyché o alma. Se trata de "un tipo peculiar de forma, de pattern: la de los seres naturales vivos, que se diferencia de la de los seres naturales no vivos porque tiene un grado mayor de actividad formalizadora (entelécheia) y se le caracteriza como inmaterial." (Choza: 1988, 100) Pero la inmaterialidad del ser vivo debe distinguirse de la inmaterialidad de otra forma, como una melodía, o las reglas de un juego.

Como es obvio, todos los procesos de velocidad finita se pueden medir: todos ellos duran o tardan: pertenecen al mundo físico. Pero si hubiera algún proceso de velocidad infinita no duraría, no tardaría. [A]sí es como caracterizan Aristóteles, Descartes y Hegel lo inmaterial [...]: lo que no está distendido espaciotemporalmente. [...] Procesos de velocidad infinita y tiempo cero son, precisamente, la constitución de un organismo vivo cualquiera [...] a partir de un conjunto de elementos y procesos materiales; cualquier acto de sentir, por ejemplo, ver, y cualquier acto mental, por ejemplo, pensar. (Choza, 1988: 105)

Choza apela a la analogía de la cibernética para explicar la enorme diferencia entre la vida humana y la vida artificial. A modo de ejemplo, una diferencia hombre-máquina es la que se refiere a la capacidad funcional de una neurona: "[e]n algunas funciones la neurona sobrepasa a todos los elementos electrónicos de conexión conocidos, y necesita mucho menos espacio y energía de mantenimiento. Sólo en cuanto a la velocidad funcional es inferior a los elementos electrónicos." (Steinbuch, 1975: 69-70) ${ }^{5}$

Se puede decir que, a nivel sub-atómico, la célula neuronal y un chip tienen electrones, protones y neutrones similares, pero algo pasa en el nivel

${ }^{5}$ Cita prestada de Choza: 1988, 113. 
molecular para que neurona y chip tengan una forma esencialmente diferente de autorregulación, hasta el punto de producirse tan alta diferencia energética como la del ejemplo citado.

La cibernética, desarrollada por Norbert Wiener en 1948, trata acerca del control y comunicación de seres vivos y máquinas en cuanto a su autorregulación u "homeostasis". Se habla de "homeostasis vital" cuando se refiere a los seres vivos y, analógicamente, de "homeostasis cibernética" cuando se trata de las máquinas.

Etimológicamente, "cibernética" proviene del griego Kybernetiké que es el arte de gobernar una nave; y quien gobierna la nave, el piloto, es el kibernétes. Para Platón, el alma o psique es quien dirige o "pilota" el cuerpo. Y esa psique es también eidos, algo de naturaleza ideal y preexistente. Así tenemos una doble función del concepto alma: por ser ideal y preexistente, es eidos; y por ser piloto del cuerpo, es kibernétes. (Cfr. Choza, 1988: 113).

Aristóteles coincide en el concepto platónico de alma, pero no está de acuerdo en que sea un kibernétes. Admite que el alma sea un eidos pero no preexistente y no se superpone a un cuerpo (soma) de forma temporal. El alma es más bien entelécheia del cuerpo, es decir: "como un eidos o como una forma que tiene en sí la enérgeia suficiente como para realizarse o llevar a cabo su propio despliegue hasta alcanzar la madurez o plenitud que por su propia índole le corresponde." (Choza, 1988: 114) ${ }^{6}$

Aristóteles deja a un lado el concepto eidos o "idea platónica", y lo reformula como morphé, "forma", porque se opone a las ideas o idealidades que son puras o separadas, y también porque no son reales al no ser "activas". Para Aristóteles ser real significa ser activo, y lo activo es causal. Ante esta falta de causalidad, Aristóteles critica a Platón diciendo, "lo que con más perplejidad se preguntaría uno es qué aportan las Especies a los entes sensibles, tanto a los eternos como a los que se generan y corrompen, pues no

\footnotetext{
${ }^{6}$ Además, Choza señala que: "Entelécheia, en-télos-echein, significa alcanzar su propia plenitud, el propio fin y sostenerse en él. Aristóteles, Metafísica, V, 16. La etimología de entelécheia está tomada de la obra de M. Heidegger, Introducción a la metafísica, Nova, Buenos Aires, 1959." (Choza, 1988: 114, nt29)
} 
causan en ellos ni movimiento ni ningún cambio." (Aristóteles, Metafísica, 991a: 9-11; Cfr. Choza, 1988: 115 nt30.)

En efecto, la psique en cuanto eidos puede captar perfectamente el plano de lo pensado porque es pura idea, y guarda en ella los contenidos de la inteligencia de forma pura; pero por ser pura, no cambia, permanece siempre. Por eso, para Platón, pensar es recordar lo que ya existía. También por eso, el cuerpo es "cárcel" del alma, ella está capturada hasta que se libere. El alma se une al cuerpo sólo temporalmente, para habitar un mundo material, pero el cuerpo es un accesorio.

En cambio, Aristóteles, al considerar el alma en un ser vivo que tiene cuerpo físico precisa de una entelequia que le vaya dirigiendo hacia su fin. Para que haya vida orgánica es preciso que haya un alma y un cuerpo.

Choza sintetiza la diferencia entre una máquina con sistema cibernético y un organismo viviente del siguiente modo:

a) Un sistema homeostático cibernético (la máquina) es la materialización o positivación de una forma, lo que se logra dotando a la forma de una capacidad energética ab extrínseco. Así, forma y energía están disociadas: no hay una copertenencia recíprocamente intrínseca entre ambas, y lo que resulta es una unidad funcional artificial.

b) Un sistema homeostático vivo, un organismo viviente, es la formalización de una materia, lo que se logra por unificación ab intrínseco de todos los elementos materiales. Así, lo que resulta es un organismo vivo, lo que en la filosofía aristotélica se llamó una unidad substancial. (Choza, 1988: 116) ${ }^{7}$

Además de esto, resulta muy original la diferencia fundamental que propone entre un ser vivo y una máquina, y es que la máquina no tiene "cuerpo", en sentido propio:

${ }^{7}$ En la nota 31, Choza aclara que la contraposición entre materialización de la forma y la formalización de la materia está tomada de Leonardo Polo. 
[L]a máquina no tiene cuerpo porque no tiene psique (acto primero del cuerpo físico organizado): no es una estructura funcional dotada de la energía suficiente para cumplirse por sí misma.

Una máquina no tiene cuerpo porque no hay en ella una copertenencia recíprocamente intrínseca entre forma, energía y elementos materiales, sino que los elementos materiales son puestos desde fuera (y son todos recambiables) con arreglo a un proyecto ideal, que no tiene energía para realizar la acción de poner su propia estabilidad, su propia realización. $\left(\right.$ Choza, 1988: 117) ${ }^{8}$

Finalmente Choza, apoyándose en von Bertalanffy, afirma que "el organismo viviente es un sistema abierto, y que no tiene como máximo objetivo el mantenerse, sino que crece y se expande, pues la vida es fecundidad, lo cual no sucede en un sistema cibernético." (Choza, 1988: 117. Cfr. von Bertalanffy, 1971: 118 y ss.) Este crecimiento y expansión requiere traspasar el equilibrio homeostático para formar algo nuevo, lo que ya no obedece a la cibernética.

[M]ás netamente se puede expresar la diferencia, en función de la noción de cuerpo, diciendo que una máquina no puede morir: no puede darse en ella una ruptura de la unidad (copertenencia recíprocamente intrínseca) entre actividad formalizadora y los elementos materiales que la componen, porque en ella esa unidad no la hay, y esa ruptura es, precisamente, lo que se llama muerte de un organismo viviente. La unidad de una máquina es, pues, extrínseca, y, por tanto, muy débil: es una unidad llamada justamente artificial. [...] La unidad de un organismo viviente viene dada en cambio en lo que se viene llamando psique, y ahora resulta más patente que la psique no es una función del sistema. (Choza, 1988: 118)

Desde la ontología, esa diferencia ser humano-máquina aumenta exponencialmente al tratarse de la inteligencia humana ya que sus propiedades de índole inmaterial hacen que las comparaciones con las máquinas no sean solamente en el nivel del pensamiento, que sería la "razón o diánoia" en

${ }^{8}$ El subrayado es de la fuente. 
Aristóteles, sino en el nivel de la captación intuitiva y de los primeros principios, que sería el "intelecto o noús".

\section{Inteligencia artificial y noús}

Muchas veces los términos referidos a las funciones humanas se aplican a las máquinas y son asumidas de forma unívoca por numerosos científicos y profesionales no científicos que trabajan con las nuevas tecnologías. Existe un fenómeno que consiste en no discernir correctamente las diferencias entre las capacidades naturales humanas y las artificiales de los ordenadores. Esto lo he explicado en otro trabajo poniendo el acento en la actitud humana que tiende a "antropomorfizar" aquello con lo que empatiza (Cfr. Acosta, 2018: 106-10).

Como hemos visto, la IA se apoya fundamentalmente en las analogías, su forma de hacerlo es la técnica de simulación. En algunos casos, las máquinas realizan funciones que representan, recrean o imitan aspectos de la realidad. Tenemos experiencia de ello en lo que se denomina "realidad virtual". En la IA, no se recrea un mundo en el que las máquinas intentan introducir a las personas en un mundo de fantasía, sino que las máquinas entran en contacto con el mundo real en forma de virtualidades. Así, Watson participa en Jeopardy! imitando a un humano, cuando realmente es una máquina que calcula y procesa millones de datos en un brevísimo lapso sin ningún tipo de sentimientos. Las máquinas no pueden cometer errores, quienes lo hacen son los humanos que preparan los algoritmos o quienes construyen los circuitos integrados. Las máquinas o las "máquinas que hacen máquinas" solamente siguen las instrucciones de los algoritmos.

Los ingenieros, programadores y analistas de sistemas son quienes determinan la estrategia y la lógica de codificación que hará parecer que un robot responda adecuadamente a una pregunta porque éste sigue patrones de respuesta, patrones de movimiento o patrones de cálculo. 
¿Cómo lo hacen? Por ejemplo, cuando pregunto al asistente electrónico de mi móvil: "Siri, ¿̇quién soy?” Me responde "Eres Miguel”. Lo sabe porque a través de un analizador de voz ha identificado la pregunta mediante palabras clave. En este caso: "quién” y "soy”. Luego, esas palabras se buscan en una base de datos, donde se almacenan millones de datos clasificados en una "tablas" — que son como una hoja de Excel—y comienza el proceso de búsqueda. En este caso, se accede a la parte en la que se almacenan los datos de identificación del propietario del móvil.

Otro ejemplo: cuando uno accede a una página de Internet, hay unos algoritmos que hacen que lo que escribimos se vaya almacenando en un archivo donde hay una colección de palabras similares y según el número de veces que uno utiliza la palabra elegida, se ofrecerán como alternativas otras palabras similares que pertenecen al mismo dominio en el que se encuentra la palabra original. Por eso cuando entramos en Amazon y pedimos un libro determinado, en los márgenes o en la parte inferior de la pantalla aparecen libros de temas similares. También los correctores y los traductores funcionan comparando palabras de bases de datos lingüísticas.

El proceso es iterativo y se va mejorando cada vez más conforme a los datos que se recojan y según como se ordenen mediante la técnica llamada "Deep learning". Pero esto no es "pensar" propiamente dicho.

Otro ejemplo: hay programas que escriben poemas. El programador desarrolla la aplicación "Escribir poemas" según las reglas métricas para componer un terceto o un soneto. Una vez terminado el programa, cuando se ejecuta el algoritmo, la aplicación busca el título del poema junto con otras palabras clave que le da el usuario; luego relaciona las palabras directa o indirectamente y las ordena sintáctica y semánticamente, que también se programó previamente para componer el poema. 
Las técnicas de los motores de búsqueda son fruto de la inteligencia de los programadores y requieren un alto conocimiento de "ontología informática" y matemática en el campo de la Investigación de Operaciones donde se aplican las teorías de juegos, optimización, análisis estadísticos, teorías de la complejidad, entre otras. Uno de los secretos mejor guardados que tiene Google son sus motores de búsqueda, que fueron desarrollados inicialmente por dos estudiantes de postgrado de la Universidad de Stanford, y que ha sido el elemento diferenciador con respecto a otros buscadores situándolo en primer lugar y dejando atrás a Yahoo, MNS Search, AOL Search o Altavista. Pero el proceso que realizan estos motores tampoco se llama "pensar" propiamente dicho.

Aun así, se puede decir que hay una analogía extrínseca entre pensar y el procesamiento de datos: ambos deben seguir frases lógicas, aunque lo hagan de distinta forma, una a partir de su función vital, la otra a partir de circuitos electrónicos.

La mayor ventaja del procesamiento de un ordenador es la parte lógicomatemática que siempre le acompaña. Y la mayor ventaja del pensamiento humano con respecto al ordenador, es su relación con otro acto de la inteligencia humana en el que se funda: el "intelecto" o "noús". Aclaremos brevemente el concepto noús:

Pensar es el modo no sensible de conocer, orientado al objeto y a las relaciones que implica. [...] ¿Cuál es la estructura y el despliegue del pensamiento, o sea, de la facultad de captar de modo no sensible el objeto y sus relaciones? Si retrospectivamente se miran las respuestas que en la Historia de la Filosofía se han dado a esa pregunta, sorprende observar un núcleo bipolar de términos adheridos al tema del pensamiento. Este fue comprendido entre los griegos como una relación de la diánoia [...] al noús [...]; entre los latinos como una relación de la ratio al intellectus; entre los modernos, como la relación del entendimiento a la

\footnotetext{
${ }^{9}$ La ontología en el sentido informático se refiere a la conceptualización de modelos abstractos de algún aspecto del mundo que se aplican sobre todo para programar en la Web semántica. En ella se definen las características y propiedades de los principales conceptos y sus relaciones que luego serán procesados digitalmente. (Cfr. Staab, Studers (eds.), 2004) 
razón o, en términos alemanes, del Verstand a la Vernunft." (Cruz Cruz, 1994: 1314)

El intelecto (noús) antecede al proceso del pensamiento, es la condición para la diánoia donde se lleva a cabo el razonamiento lógico. El noús antecede a la diánoia porque sus procesos son inmediatos, se dan de forma intuitiva y habitual. Como diría Choza, "en tiempo cero". Aristóteles le atribuía la función del hábito de los primeros principios y la consciencia. La consciencia no piensa, "advierte", es un darse cuenta cuando estamos en estado de vigilia, e incluso se puede dar un paso más, si hablamos de la consciencia reflexiva: uno se da cuenta de que se da cuenta. Es la autoconsciencia. Nada de esto tienen los ordenadores porque, ya de entrada, no pueden procesar lo inmaterial.

\section{Bibliografía empleada}

— M. Acosta, "IA: singularidad tecnológica y antropomorfismo", en: Ideas 12. Sobre Inteligencia Artificial, ¿Conciencia Artificial?, de Natalia López Moratalla, 2018: 103-120.

— Aristóteles, Metafísica de Aristóteles, Barcelona, Gredos, 1982, Traductor Valentín García Yebra.

— Ch. Barnatt, Digital Genesis. The Future of Computing, Robots and AI, (2017), Publisher Explaining Computers.com.

— J. Brandon, "An AI god will emerge by 2042 and write its own bible. Will you worship it?” Ver: https://venturebeat.com/2017/10/02/an-ai-god-will-emerge-by-2042-and-write-itsown-bible-will-you-worship-it/. (Última visita: 14 julio 2018)

- J. Cruz Cruz, Intelecto y razón. Las coordenadas del pensamiento clásico, Pamplona, EUNSA, 1994.

— J. Choza, Manual de Antropología Filosófica, Madrid, Rialp, 1988.

— Stanford University Webpage: https://ai100.stanford.edu/ (Última visita: 14 julio 2018).

— Magnet.com. Ver: https://magnet.xataka.com/preguntas-no-tan-frecuentes/ias-no-tevan-quitar-trabajo-granjas-bots-humanos-descubiertas-escandalo-gmail (Última visita: 17 julio 2018).

— R. Jordana Butticaz, La ciencia en el horizonte de una razón ampliada. La evolución y el hombre a la luz de las ciencias biológicas y metabiológicas, Madrid, Unión Editorial, 2016. 
— N. Jouve, Explorando los genes. Del Big-Bang a la nueva biología, Madrid, Ediciones Encuentro, 2008.

- R. Kurzweil, The Singularity Is Near. When Humans Transcend Biology, New York, VikingPenguin Group, 2005.

- P. McCorduck, Machines Who Think: A Personal Inquiry into the History and Prospects of Artificial Intelligence (2004), Natick (MA), A. K. Peters, Ltd.

- Th. Nagel, La mente y el cosmos. Por qué la concepción neo-darwinista materialista de la naturaleza es, casi con certeza, falsa, Madrid, Biblioteca Nueva, 2014. Traducción y prólogo: Francisco Rodríguez Valls.

- N.J. Nilsson, The Quest for Artificial Intelligence. A History of Ideas and Achievements, Cambridge UK, Cambridge University Press, 2010.

- E. Schöedinger, ¿Qué es la vida?, Barcelona, Tusquets Editores, 2001.

— S. Staab \& R. Studer, Handbook on Ontologies, Berlin, Springer-Verlag, 2004.

— K. Steinbuch, "Principios de una antropología cibernética", en: Antropología Biológica, 1975 (55-100).

—A. Turing, "Computing Machinery and Intelligence", en: Mind, 1950 (LIX, 236): 433460. Ver: https://doi.org/10.1093/mind/LIX.236.433

- A. Turing, Maquinaria computacional e Inteligencia, Universidad de Chile trad. Cristóbal Fuentes Barassi, 1950.

— L. von Bertalanffy, Robots, hombres y mentes. La psicología en el mundo moderno, Madrid, Guadarrama, 1971.

Miguel Acosta

macosta@ceu.es 